\title{
Mesenchymal stem cells ameliorate the histopathological changes in a murine model of chronic asthma
}

\author{
Fatih Firinci ${ }^{\mathrm{a}, *}$, Meral Karaman ${ }^{\mathrm{b}}$, Yusuf Baran ${ }^{\mathrm{c}}$, Alper Bagriyanik ${ }^{\mathrm{d}}$, Zeynep Arikan Ayyildiz ${ }^{\mathrm{a}}$, Muge Kiray ${ }^{\mathrm{d}}$, \\ Ilknur Kozanoglu ${ }^{\text {e, Osman Yilmaz }}{ }^{\text {, }}$, Nevin Uzuner ${ }^{\mathrm{a}}$, Ozkan Karaman ${ }^{\mathrm{a}}$ \\ a Pediatric Allergy and Immunology, Faculty of Medicine, Dokuz Eylul University, Izmir, Turkey \\ ${ }^{b}$ Multidisciplinary Laboratory, Faculty of Medicine, Dokuz Eylul University, Izmir, Turkey \\ ${ }^{c}$ Izmir Institute of Technology, Department of Molecular Biology E Genetics, Gulbahce Campus, Urla, Izmir, Turkey \\ d Department of Histology, Faculty of Medicine, Dokuz Eylul University, Izmir, Turkey \\ e Baskent University, Department of Bone Marrow Transplantation, Adana Education and Research Hospital, Adana, Turkey
}

\section{A R T I C L E I N F O}

\section{Article history:}

Received 6 October 2010

Received in revised form 4 February 2011

Accepted 7 March 2011

Available online 23 March 2011

\section{Keywords:}

Mesenchymal stem cells

Chronic asthma

Antiinflammatory

Treatment

Mice

\begin{abstract}
A B S T R A C T
Asthma therapies are effective in reducing inflammation but airway remodeling is poorly responsive to these agents. New therapeutic options that have fewer side effects and reverse chronic changes in the lungs are essential. Mesenchymal stem cells (MSCs) are promising for the development of novel therapies in regenerative medicine. This study aimed to examine the efficacy of MSCs on lung histopathology in a murine model of chronic asthma. BALB/c mice were divided into four groups: Group 1 (control group, $n=6$ ), Group 2 (ovalbumin induced asthma only, $\mathrm{n}=10$ ), Group 3 (ovalbumin induced asthma + MSCs, $\mathrm{n}=10$ ), and Group 4 (MSCs only, $\mathrm{n}=10$ ). Histological findings (basement membrane, epithelium, subepithelial smooth muscle thickness, numbers of goblet and mast cells) of the airways and MSC migration were evaluated by light, electron, and confocal microscopes. In Group 3, all early histopathological changes except epithelial thickness and all of the chronic changes were significantly ameliorated when compared with Group 2. Evaluation with confocal microscopy showed that no noteworthy amount of MSCs were present in the lung tissues of Group 4 while significant amount of MSCs was detected in Group 3. Serum NO levels in Group 3, were significantly lower than Group 2. The results of this study revealed that MSCs migrated to lung tissue and ameliorated bronchial asthma in murine model. Further studies are needed to evaluate the efficacy of MSCs for the treatment of asthma.
\end{abstract}

(c) 2011 Elsevier B.V. All rights reserved.

\section{Introduction}

Asthma is a chronic disease characterized by reversible airway obstruction, airway inflammation and remodeling [1]. Current strategies for the management of asthma focus on suppressing airway inflammation [2]. Inhaled glucocorticoids are currently the mainstay of asthma therapy although several side effects may arise when they are used at high doses or for a prolonged time [3]. Airway remodeling consists of progressive structural changes in the composition, content, and organization of the cellular and molecular constituents of the airway wall [4]. Although current asthma therapies are effective in reducing inflammation, airway remodeling is poorly responsive to current therapies, such as inhaled corticosteroids, antileukotrienes, and theophylline [4,5]. For this reason, new therapeutic options are required.

Mesenchymal stem cells (MSCs) are emerging as a therapeutic modality in various inflammatory diseases. MSCs have the potential to differentiate into various connective tissue lineages including adipose

\footnotetext{
* Corresponding author. Tel.: +90 232 4123664; fax: +90 2324123649. E-mail addresses: fatih.firinci@deu.edu.tr, fatihfirinci@yahoo.com (F. Firinci).
}

tissue, marrow stroma, cartilage, tendon and bone [6]. Additionally, studies during the last decade have suggested that MSCs may have more plasticity and are able to differentiate into bronchial and alveolar epithelium, vascular endothelium, and interstitial cell types [7]. MSCs can be isolated from multiple tissues including adipose tissue, skeletal muscle, synovium, spleen, thymus, blood, lung, fetal blood, and amniotic fluid [8]. The most accessible and the best characterized source of MSCs is the bone marrow although they are found in relatively small numbers with an estimate of about 10 MSCs for 1 million total bone marrow cells [9].

However, to the best of our knowledge, there is no report in the medical literature regarding the efficacy of MSCs in the treatment of asthma. The aim of the present study was to investigate the efficacy of MSCs on lung histopathology in a murine model of asthma.

\section{Materials and methods}

\subsection{Experimental animals}

Specific pathogen-free, 6- to 8-week-old, female BALB/c mice, weighing 18 to $20 \mathrm{~g}$, were maintained in the animal laboratory of 
Dokuz Eylul University. They were kept in hygienic macrolene cages in air-conditioned rooms and allowed ad libitum with food and water on a 12-hour light/12-hour dark cycle. All experimental procedures were prepared according to the requirements of the Animal Care and Ethics Committee of the Dokuz Eylul University. Thirty-six BALB/c mice were divided into four groups; Group 1 (control group, $\mathrm{n}=6$ ), Group 2 (ovalbumin induced asthma only, $\mathrm{n}=10$ ), Group 3 (ovalbumin induced asthma + MSC, $\mathrm{n}=10$ ), and Group 4 (MSC only, $\mathrm{n}=10)$.

\subsection{Sensitization and inhalational exposure}

$\mathrm{BALB} / \mathrm{c}$ mice are high responders to ovalbumin [10]. Mice in control group were not exposed to any intervention. The mice in study Groups 2 and 3 were sensitized via two intraperitoneal injections, on days 0 and 14 of the experiment, of $10 \mu \mathrm{g} / 0.1 \mathrm{ml}$ chicken egg albumin (ovalbumin, grade $\mathrm{V}, \geq 98 \%$ pure; Sigma, St. Louis, MO, USA) with alum as an adjuvant. After the sensitization, the mice in study Groups 2 and 3 were exposed to aerosolized ovalbumin for 30 min per day on three days a week for eight weeks, beginning from the 21st day of the study. The mice in control group were administered normal saline with alum intraperitoneally on days 0 and 14 of the experiment and exposed to aerosolized saline for 30 min per day on three days a week for eight weeks, beginning from the 21st day of the study [11]. Exposures were carried out in a whole body inhalation exposure system. Temperature and relative humidity were maintained between $20-25{ }^{\circ} \mathrm{C}$ and $40-60 \%$, respectively. A solution of $2.5 \%$ ovalbumin in normal saline was delivered by aerosolization via compressed air to a sidestream jet nebulizer injected into a chamber. The aerosol generated by this nebulizer comprised $>80 \%$ particles with a diameter of $<4 \mu \mathrm{m}$. Particle concentration was maintained in the range of 10 to $20 \mathrm{mg} / \mathrm{mm}^{3}$ [11].

\subsection{Generation and administration of mesenchymal stem cells}

\subsubsection{Bone marrow harvest}

In order to isolate mesenchymal stem cells, after sacrificing 6- to 8week-old BALB/c mice obtained from the Dokuz Eylul University, femurs and tibias were dissected away from attached muscle and connective tissue; the ends of the bones were removed. Bone marrow was extruded by inserting a 21-gauge needle into the shaft of the bone with cuts on both ends and flushing it with $1 \mathrm{ml}$ of Dulbecco's modified Eagle's medium (DMEM; Biological Industries, Israel) supplemented with $10 \%$ fetal bovine serum (FBS). The marrow plugs were dispersed by passage through a 16-gauge needle and the marrow was filtered through a $75-\mu \mathrm{m}$ filter. Cells were plated in tissue culture flask.

\subsubsection{Isolation and culture of mesenchymal stem cells (MSCs)}

Between 10 and $15 \times 10^{6}$ whole marrow cells were placed in a $75 \mathrm{~cm}^{2}$ tissue culture flask in DMEM containing 15\% fetal bovine serum (FBS), $2 \mathrm{mmol} / \mathrm{l} \mathrm{L-glutamine,} 100 \mathrm{U} / \mathrm{ml}$ of penicillin and $100 \mu \mathrm{g} / \mathrm{ml}$ of streptomycin (Biological Industries, Israel) at $37^{\circ} \mathrm{C}$ in a humidified atmosphere of $5 \%$ carbon dioxide. After $72 \mathrm{~h}$, the nonadherent cells were removed by changing the medium. The medium was completely replaced every 3 days and nonadherent cells were discarded. Cultured MSCs were observed under inverted microscope to assess the level of expansion and to verify the morphology at each culture medium change. In order to prevent the MSCs from differentiating or slowing their rate of division, each primary culture was replaced (first passage) to 3 new flasks when the cell density within colonies became $80-90 \%$ confluent, approximately 2 weeks after seeding. The adherent cells were released from flasks with $0.25 \%$ trypsin in $1 \mathrm{mmol} / \mathrm{l}$ sodium ethylenediaminetetraacetic acid (EDTA, Sigma, St. Louis, MO, USA). After the twice-passaged cells became nearly confluent, they were harvested and used for the experiments [12].

\subsubsection{Transfection of MSCs by GFP}

In order to track stem cells in vivo, cells were transfected with pEGFP-N1 Vector including GFP encoding gene (ClonTech, USA). Lipid based transfection was performed with PolyFect Transfection Reagent according to the kit instructions (Qiagen, USA). Briefly, $5 \times 10^{5}$ cells were plated and grown when they reach $60 \%$ confluency. The day before transfection, MSCs grown in $75 \mathrm{~cm}^{2}$ flasks were detached by trypsin-EDTA treatment and replated into a new sterile $75 \mathrm{~cm}^{2}$ flask at a density of $1.6 \times 10^{6}$ cells in $8 \mathrm{ml}$ of complete media. The cells were incubated at $37^{\circ} \mathrm{C}$ and $5 \% \mathrm{CO}_{2}$. The next day, transfection mixture including $10 \mu \mathrm{g}$ of plasmid DNA and total volume was transferred drop wise onto the cells in the flasks. The flask was gently swirled in an attempt to ensure uniform distribution of the complexes. Finally, cells were incubated overnight with the complexes and then were visualized under the fluorescent microscope [12].

\subsubsection{Flow cytometry}

The cells were incubated with antibodies against CD45 PC5 (Beckman Coulter, Marsillia, France), NG2 PE (Beckman Coulter), CD73 PE (Becton-Dickinson, Bioscience Pharmingen, San Diego, CA, USA), and CD105 FITC (Serotec, Oxford, UK). Fluorescence histograms were obtained by recording 20,000 cells/sample at a flow rate of approximately 200 cell events/s. Experiments were conducted using Coulter Epics XL-MCL and flow cytometric data were analyzed using EXPO 32 ADC software (Beckman Coulter Inc, Miami, FL, USA) [13]. Flow cytometry analysis demonstrated that there were significant expressions of MSC specific antigens (CD105, CD73, and NG2) and absence of hematopoietic marker antigen (CD45).

\subsection{MSC administration}

Flow cytometry demonstrated that the cells were MSCs. Subsequently, $10^{6}$ MSCs were administered via an insulin syringe from the tail vein following OVA nebulization under superficial sedation to each of the 10 mice in both Groups 3 and 4 (Fig. 1).

\subsection{Histopathological analysis}

Animals were sacrificed after two different time periods by an overdose of ketamine after last MSC administration. First, half of the animals were sacrificed at the end of one week in order to analyze the histological findings of the lung tissue and whether MSCs migrated to the inflamed lung tissue or not. Second, remaining mice were sacrificed at the end of the second week in order to evaluate the histopathological features of inflammation in the lungs. Two investigators who were blinded to the treatment groups interpreted the histopathology. Tissue specimens were obtained from the mid zone of the left lung of mice. Samples were fixed in 10\% formalin for light microscopic evaluation. Some tissue samples of 1 to $2 \mathrm{~mm}^{3}$ obtained from adjacent regions were stocked in $2.5 \%$ glutaraldehyde for electron microscopic evaluation. After fixation, samples were embedded in paraffin for light microscopic evaluation and serial sections of $5-\mu \mathrm{m}$ thickness were prepared. After choosing the first section randomly, 10 sections in each mouse were selected by skipping over 10 sections and proceeded to staining process. For light microscopic evaluation, 3 different staining processes were used. The first 10 samples were stained with hematoxylin and eosin (H\&E). In these samples general tissue features were examined and thicknesses of epithelium and subepithelial smooth muscle layers of the medium and small airways were measured. In order to evaluate the thicknesses of epithelium and subepithelial smooth muscle layers, the measurements were performed from 4 points of each airway 


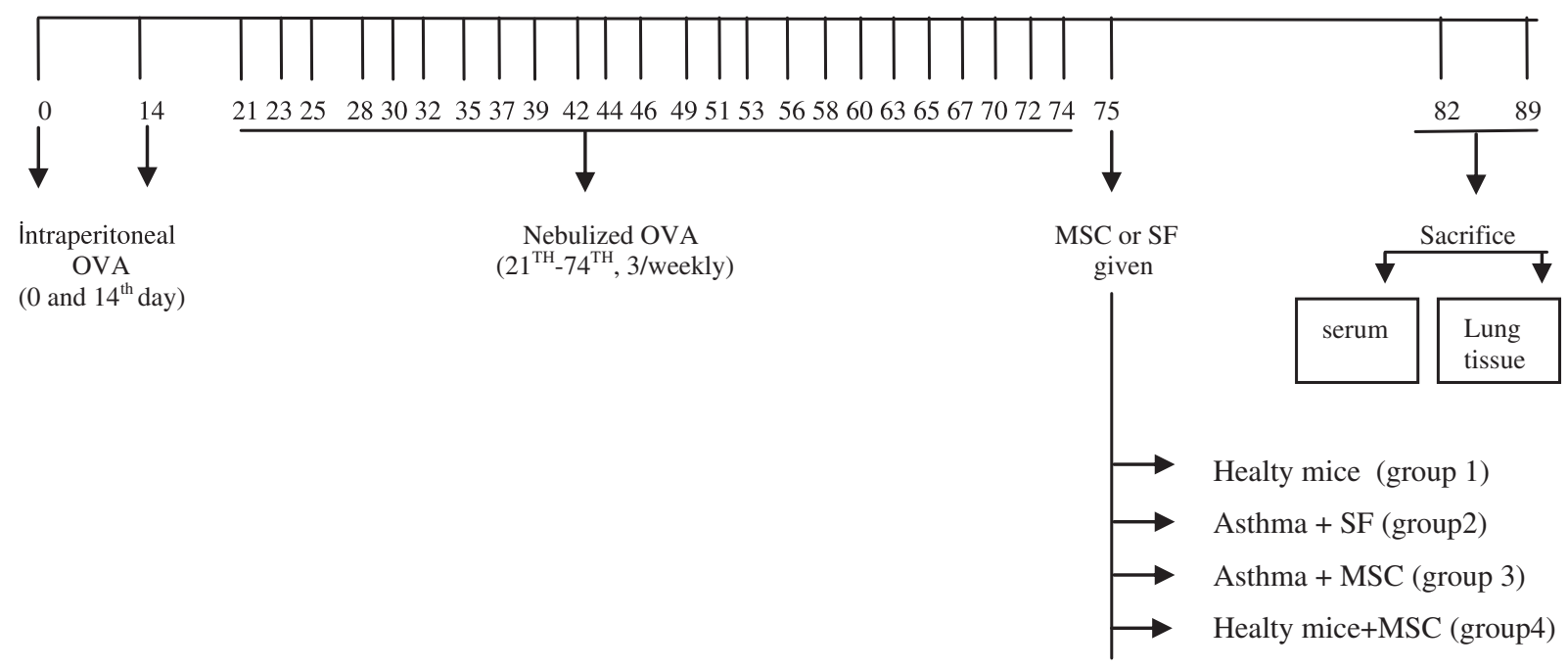

Fig. 1. Time table for mouse model of airway inflammation and treatment with MSC.

at levels of 3, 6, 9, and 12 o'clock. Considering that each section contained approximately 2 to 3 airways, nearly 20 or more airways were evaluated for each mouse.

Photomicrographs were taken by JVC TK-890-E camera (Japan), which was adapted on Olympus BH-2 RFCA model microscope (Olympus Optical, Tokyo, Japan). The histological analysis was carried out with UTHSCSA Image Tool for Windows Version 3.00 software.

The consecutive 10 sections were stained with toluidine blue and the other 10 sections with periodic acid-Schiff (PAS). Photomicrographs were taken randomly from 5 fields of each section that were stained with toluidine blue. For mast cell enumeration, a standard transparent counting frame representing an area of $16,400 \mu \mathrm{m}^{2}$ was used manually and 8 fields in each photograph were examined for each mouse. Goblet cells stained with PAS were enumerated in 10 sections of each mouse. In each section, randomly selected 3 to 5 airways were photographed. Circumferences of all airways were measured and goblet cell numbers in these areas were recorded. For standardization, goblet cell numbers in $100 \mu \mathrm{m}$ were analyzed by dividing the total goblet cell number to the total length of airway circumferences and multiplying the result by one hundred.

Tissues were embedded in EPON after follow-up process of electron microscopic evaluation. Airways were marked from the semithin sections by light microscope. Ultrathin sections were obtained and stained with uranyl acetate and lead citrate. Libra 120 Carl Zeiss EFTEM electron microscope (Oberkochen, Germany) was used for this evaluation. For each mouse, 5 to 7 ultrathin sections were achieved from each 2 blocks for evaluation of epithelium of the airway, the surrounding structures, and the intercellular connections.

For each mouse, 8 to 10 areas were photographed by Trondle ( $2048 \times 2048$ pixel) digital camera, attached to the electron microscope. Thicknesses of the basement membrane of the respiratory epithelium were measured from 20 points of preparations at equal distances to each other and the data were recorded in sequence.

In order to analyze whether MSCs migrated to the lung tissue, confocal microscopic evaluation was made by a blinded investigator.

\subsection{Measurements of serum NO levels}

Serum NO level was measured with Griess method; $100 \mu \mathrm{l}$ serum sample was mixed with an equal volume of Griess reagent (naphthyl ethylene-diamine dihydrochloride, \% $0.15 \mathrm{mM}$; o-phosphoric acid in sulfanilamide \% 1,5) in microtiter plates (Maxisorb immunoplate, NUNC) and was stored at room temperature for ten minutes [14].

\subsection{Statistical analysis}

SPSS 11 package program was used for the statistical analysis. Data were presented as mean \pm standard deviation (SD) (minimummaximum). The comparisons between all groups were conducted by using Kruskal-Wallis method. When differences were statistically significant, Mann-Whitney U test was used for group comparisons. $\mathrm{P}<0.05$ was considered statistically significant.

\section{Results}

Histopathologic results, serum NO levels and the migration of MSCs to the lung tissue of thirty-six BALB/c mice divided into four groups [Group 1 (control group, $n=6$ ), Group 2 (ovalbumin induced asthma only, $n=10$ ), Group 3 (ovalbumin induced asthma + MSC, $\mathrm{n}=10$ ), and Group 4 (MSC only, $\mathrm{n}=10$ )] were evaluated.

Flow cytometry analysis demonstrated that there were significant expressions of MSC specific antigens (CD105, CD73, and NG2) and absence of hematopoietic marker antigen (CD45) (Fig. 2A-D).

In order to demonstrate the establishment of asthma model, we compared control Group 1 (non asthmatic) with Group 2 (asthmatic, placebo).

In the chronic asthma Group 2 (placebo), the numbers of mast cells and goblet cells as well as the thickness of basement membrane, epithelium, and subepithelial smooth muscle layer were significantly higher when compared to the control group (Table 1). Besides, the disrupted respiratory epithelium, perivascular and peribronchial mononuclear cell infiltration (Fig. 3), increased number of degranulated goblet cells in secretory phase, and secretory granules released to lumen were demonstrated in microscopic images (Fig. 3). These results demonstrated that the model was successfully established.

In the early phase of Group 3; the thickness of basement membrane and subepithelial smooth muscle layer as well as the number of mast and goblet cells were significantly smaller than the early phase of Group 2 (Table 2, Fig. 3) $(\mathrm{P}<0.05)$.

In the late phase of Group 3; the thickness of basement membrane, epithelium, and subepithelial smooth muscle layer as well as the number of mast and goblet cells were significantly smaller than the late phase of Group 2 (Table 2, Fig. 3) $(\mathrm{P}<0.05)$.

While mice in Group 4 did not have significant MSC in their lungs, all mice in Group 3 were shown to have green dots indicating labeled MSC that migrated to the inflamed lung tissues under confocal microscope (Fig. 4).

In both early and late phases, serum NO levels in Group 3, were significantly lower than Group 2 (Fig. 5). 
A

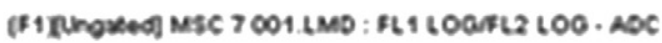

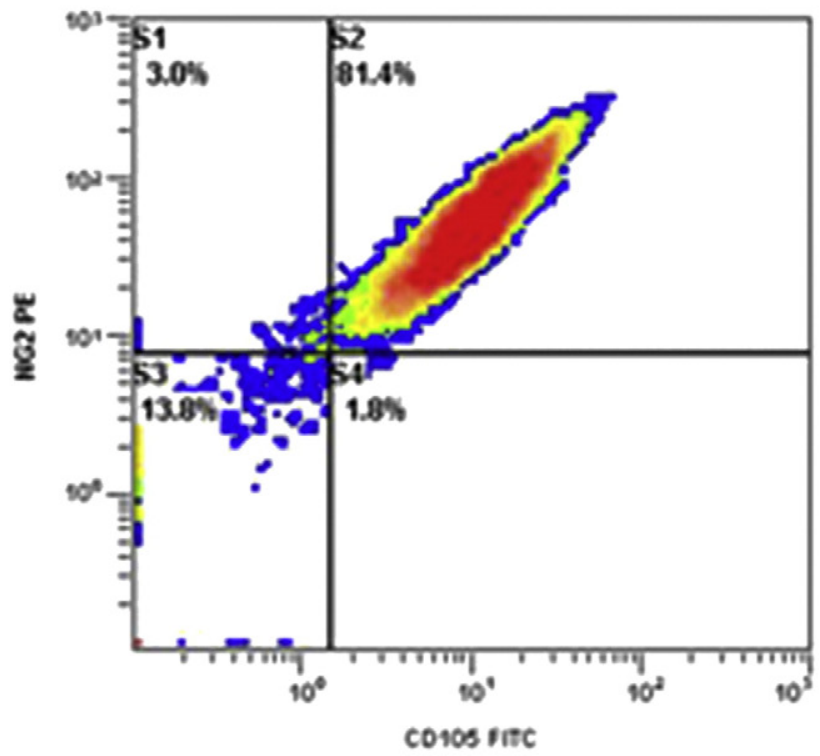

C

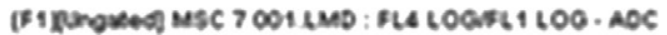

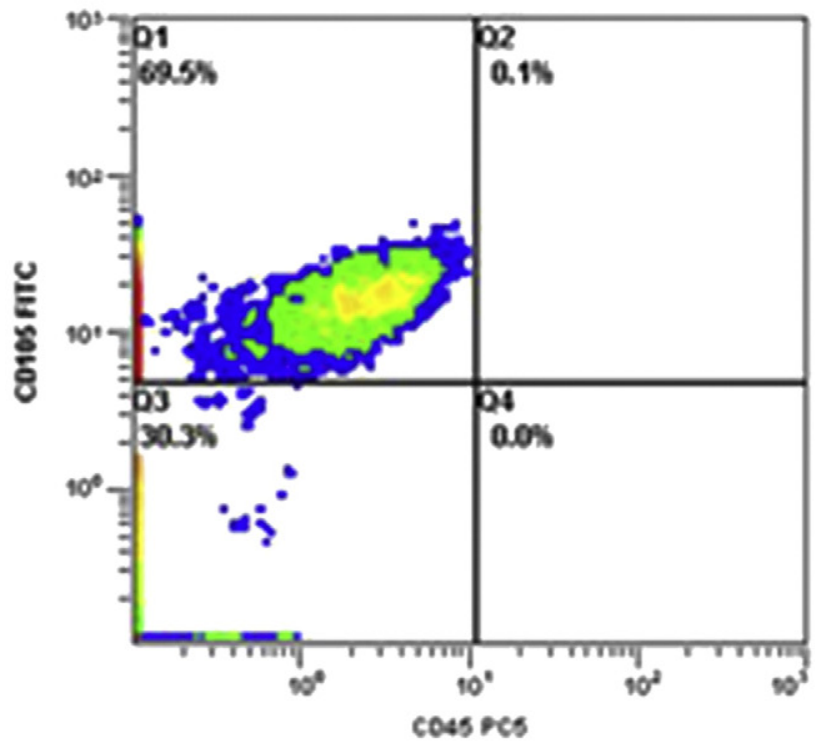

B

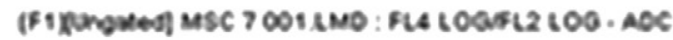

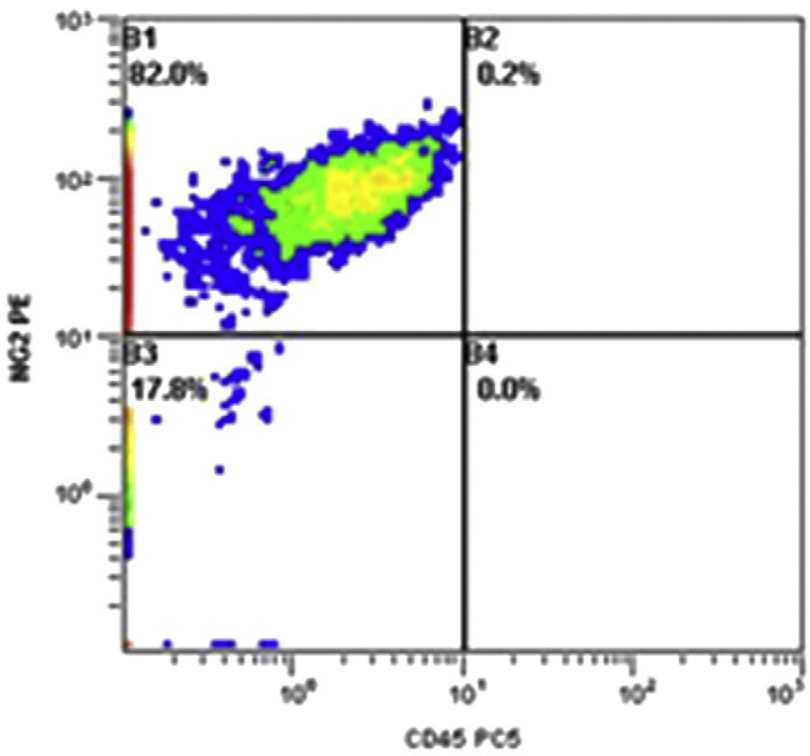

D

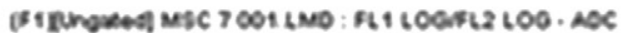

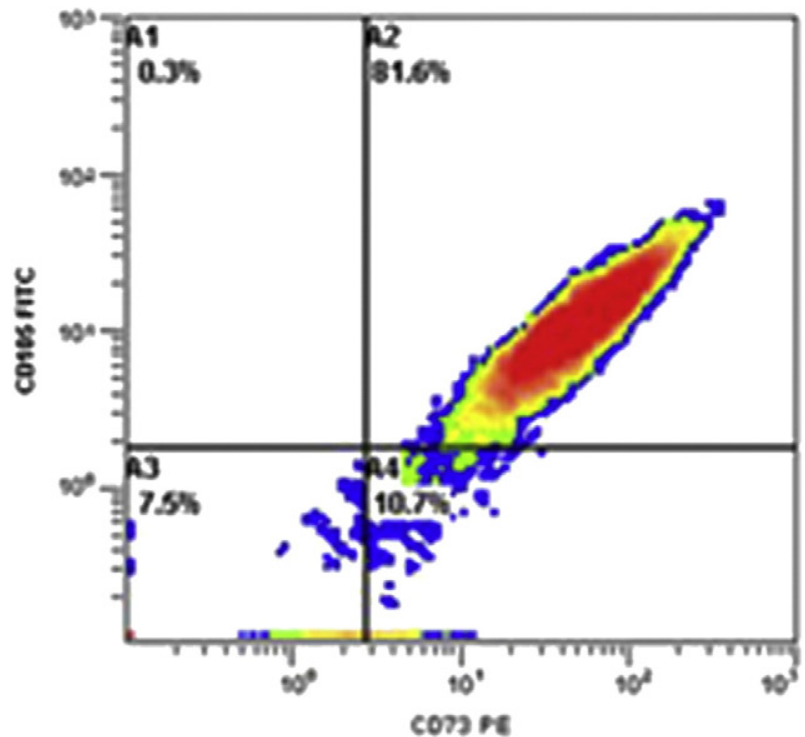

Fig. 2. The results of flow cytometric analysis indicating that the cells were MSCs since CD105, CD73, and NG2 were positive and CD45 negative.

\section{Discussion}

Airway inflammation in asthma causes subsequent structural changes called as remodeling [15]. The structural changes in

Table 1

Comparison between control (Group 1) and asthma groups.

\begin{tabular}{|c|c|c|c|}
\hline & $\begin{array}{l}\text { Control } \\
(\text { mean } \pm S D)\end{array}$ & $\begin{array}{l}\text { Asthma } \\
(\text { mean } \pm S D)\end{array}$ & $\mathrm{P}$ \\
\hline Basement membrane thickness (nm) & $262.61 \pm 16.40$ & $651.55 \pm 12.32$ & 0.00 \\
\hline $\begin{array}{l}\text { Subepithelial smooth muscle thickness } \\
\qquad(\mu \mathrm{m})\end{array}$ & $3.49 \pm 0.42$ & $9.26 \pm 1.14$ & 0.00 \\
\hline Epithelium thickness ( $\mu \mathrm{m})$ & $12.30 \pm 1.41$ & $32.26 \pm 6.08$ & 0.00 \\
\hline Numbers of goblet cells/100 $(\mu \mathrm{m})$ & $0.30 \pm 0.12$ & $2.51 \pm 0.29$ & 0.00 \\
\hline Numbers of mast cells $/ 16,400\left(\mu \mathrm{m}^{2}\right)$ & $0.71 \pm 0.12$ & $2.91 \pm 0.47$ & 0.002 \\
\hline
\end{tabular}

asthmatic airways arise as a result of an injury/repair process. Currently, drugs used for the treatment of asthma have a little effect on airway remodeling [16]. Thus we aimed to investigate the efficacy of MSCs especially on remodeling in murine model of chronic asthma.

The differentiation of MSCs into osteoblasts, chondroblasts, adipocytes, and hematopoietic supporting stroma is a well-known knowledge. In the recent reports MSCs also differentiate into non stromal tissues, including lung epithelial cells. In fact, the differentiation of MSCs into airway and lung parenchyma epithelial cells was shown in in vitro and in vivo experiments [17]. After producing the respiratory cell types from stem cells, the derivation of stem cells might be used for lung replacement/regeneration therapeutics. It is well known that MSCs can migrate to the areas of inflammation [18]. In our study, we showed that MSCs migrated to lung tissue in Group 3 with confocal microscopy. 


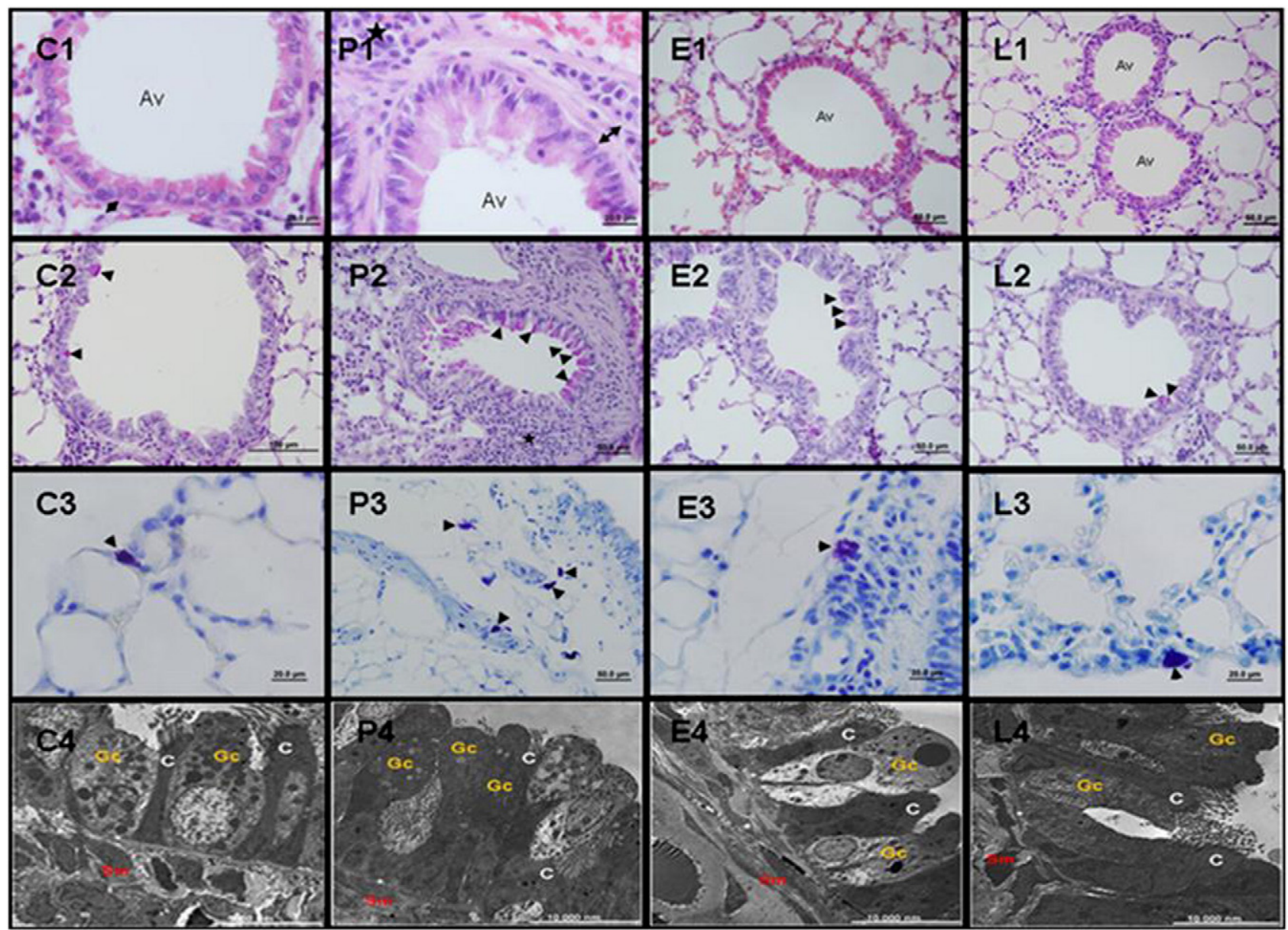

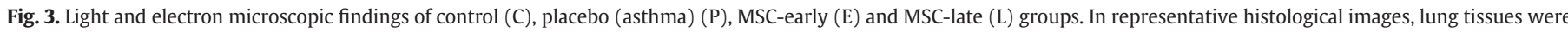

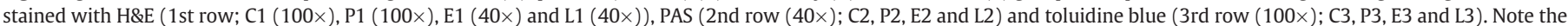

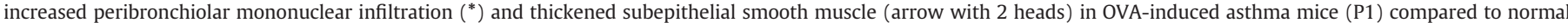

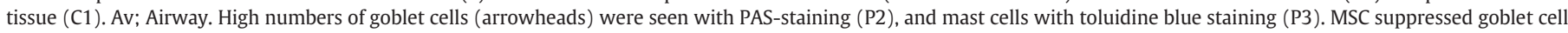

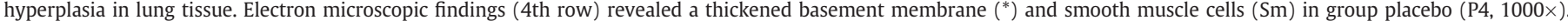
Healthy respiratory epithelium with cilia (C) and goblet cells (Gc) in groups C (1600×), E (1000×) and L (1000×).

The knowledge strongly suggests investigating the potential use of MSCs in the treatment of lung diseases $[19,20]$. For example, it is suggested that the MSCs might be used to restore the abnormal CFTR function in the cystic fibrosis that was caused by mutations of cystic fibrosis transmembrane conductance regulator [21]. Since, there was no enough study about the effect of MSCs on the asthma therapy we decided to investigate the effect of MSCs on the asthma therapy in chronic asthma model of the mice.

In the different studies, human and mouse stem cells can be produced in order to express the markers of airway or alveolar epithelial phenotype in vitro [22]. In some of these studies, it has been shown that bone marrow progenitor cells can help in repairing and remodeling of the lung in a rat model of progressive pulmonary hypertension [23]. MSCs could take a more relevant role in lung modulating of local inflammatory and immune responses. Recently, Gazdhar et al. had a study that they derived MSCs accelerating alveolar epithelial repair in vitro [24]. Moreover Lane et al. thought that differentiated embryonic stem cells, particularly enriched for a specific phenotype have a potential role in cell therapy for lung diseases [25]. In our study, we observed that MSCs helped repairing the inflammation of the lung tissue with the histopathological examination.

Table 2

Comparison between study groups.

\begin{tabular}{|c|c|c|c|c|c|c|}
\hline & \multicolumn{2}{|l|}{$\begin{array}{l}\text { Asthma } \\
(\mathrm{n}: 10)\end{array}$} & \multicolumn{2}{|l|}{$\begin{array}{l}\text { MSC + asthma } \\
(\mathrm{n}: 10)\end{array}$} & \multirow[t]{2}{*}{$\mathrm{P}^{*}$} & \multirow[t]{2}{*}{$\mathrm{P}^{\#}$} \\
\hline & $\begin{array}{l}\text { Early } \\
(\mathrm{n}: 5)\end{array}$ & $\begin{array}{l}\text { Late } \\
(\mathrm{n}: 5)\end{array}$ & $\begin{array}{l}\text { Early } \\
(\mathrm{n}: 5)\end{array}$ & $\begin{array}{l}\text { Late } \\
\text { (n: 5) }\end{array}$ & & \\
\hline Basement membrane thickness (nm) & $651.55 \pm 12.32$ & $654.30 \pm 10.65$ & $507.06 \pm 10.02^{*}$ & $333.47 \pm 15.51^{\#}$ & 0.00 & 0.00 \\
\hline Subepithelial smooth muscle thickness ( $\mu \mathrm{m})$ & $9.26 \pm 1.14$ & $9.75 \pm 0.91$ & $6.40 \pm 0.24^{*}$ & $5.07 \pm 0.52^{\#}$ & 0.047 & 0.00 \\
\hline Epithelium thickness $(\mu \mathrm{m})$ & $32.26 \pm 6.08$ & $30.35 \pm 1.50$ & $24.94 \pm 1.67$ & $16.16 \pm 0.51^{\#}$ & 0.059 & 0.002 \\
\hline Numbers of goblet cells/100 ( $\mu \mathrm{m})$ & $2.51 \pm 0.29$ & $2.41 \pm 0.22$ & $1.31 \pm 0.26^{*}$ & $1.04 \pm 0.17^{\#}$ & 0.010 & 0.045 \\
\hline Numbers of mast cells/16,400 $\left(\mu \mathrm{m}^{2}\right)$ & $2.91 \pm 0.47$ & $3.09 \pm 0.40$ & $1.51 \pm 0.27^{*}$ & $1.48 \pm 0.49^{\#}$ & 0.039 & 0.002 \\
\hline
\end{tabular}

\footnotetext{
* Comparison of the groups regarding early phase results.
}

\# Comparison of the groups regarding late phase results. 


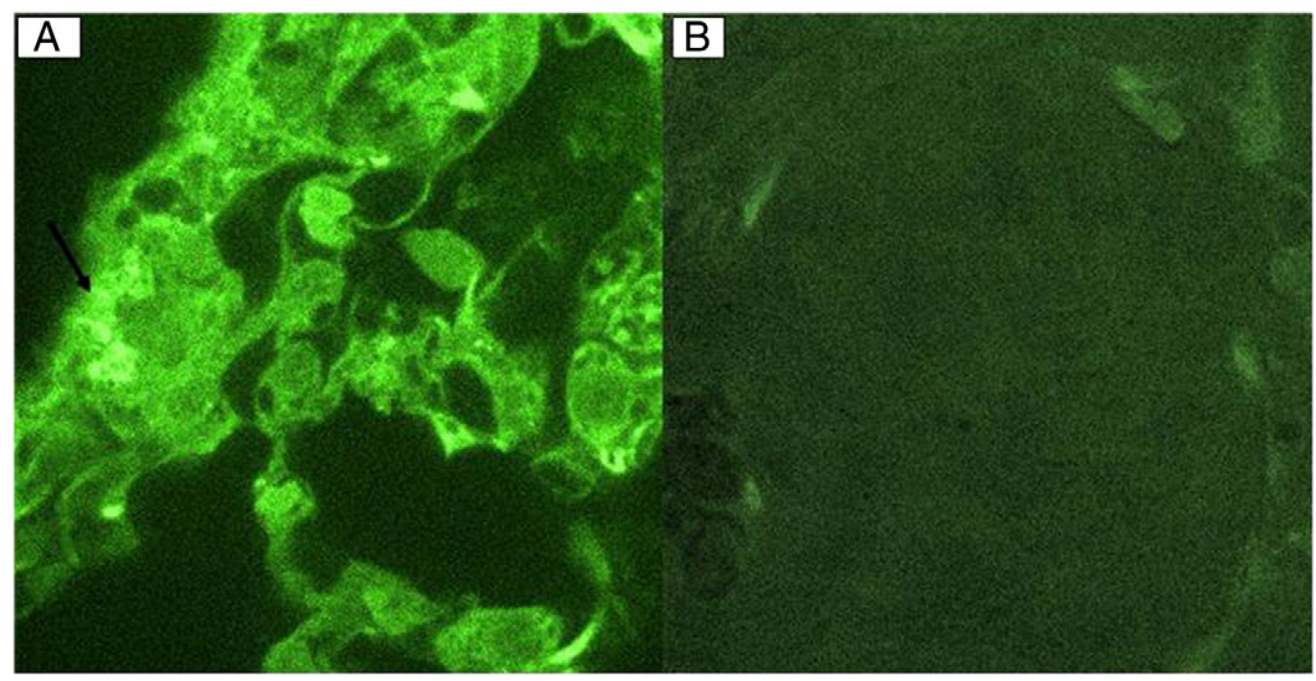

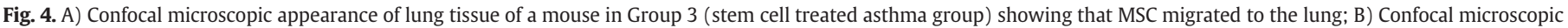
appearance of lung section of a mouse in Group 4 showing that no labeled-MSC was present ( $40 \times$; green dots represent nanocrystals of celltrackers indicating MSCs (arrow)).

Recent studies showed that intratracheal administration of MSCs could decrease lung injury. Four hours after the intratracheal endotoxin administration, application of intratracheal MSCs decreased mortality, pulmonary edema, and levels of TNFa and MIP-1b in the bronchoalveolar lavage (BAL) fluid when compared to onlyendotoxin treated mice [26]. MSCs change into bronchial or alveolar epithelium. When systemic administration of MSCs is compared with intratracheal administration of MSCs to the mice with bleomycininjured lungs, systemic administration of MSCs reduced the levels of pro-inflammatory cytokines and levels of matrix metalloproteinases 2 and 9 in the lungs $[27,28]$. These results showed that MSCs might have significant immunomodulatory effects in the lung. MSCs are also used to modulate airways inflammation in CF. However, these studies are not resulted in any routine therapeutic strategies. In our study, BAL examination could not be done for the evaluation of inflammatory cytokines (IL-4 and IL-5) because of the large numbers of the erythrocytes in the specimens.

Although MSCs are beneficial on the lung regeneration and repair, there is also evidence that they can cause or help in the development of parenchymal fibrosis. Hashimoto et al. showed that utilization of a bleomycin model in lung fibrosis up to $80 \%$ of the collagen-producing fibroblasts in the lung was found to be bone marrow-derived [29]

A

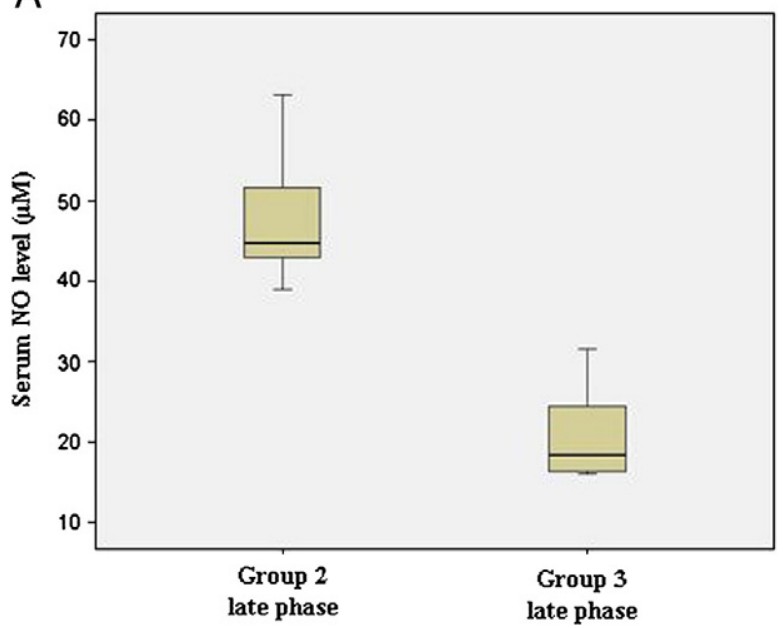

while Epperly et al. showed that administration of intravenous MSCs following lung irradiation contributed to migration of fibroblasts and myofibroblasts in areas of damage [30]. Circulating fibrocytes migrate to the injured lung tissue as a result of bleomycin challenge for collagen deposition. The effect of administration of anti-CXCL12 antibodies causes reduction in fibrotic response [31]. The most concerning issue about the characteristics of stem cell is unlimited self-renewal of the cells, potential of change into malignancy [32]. There is some evidence that these cells develop karyotype abnormalities during in vitro culture [33]. In addition, it was demonstrated that MSCs in a murine model have been associated with sarcoma development within the lung parenchyma $[34,35]$. The addition of MSCs to human breast carcinoma cells in a mouse subcutaneous xenograft model led to an increased rate of metastasis. MSCs helped the de novo secretion of CCL5 from the cells acting in a paracrine fashion resulting in increased motility and invasion of the malignant cells [36]. This influence is reversible and dependent on continued CCL5 secretion. The reason of dividing groups into early and late phases is to observe the possible adverse effect of the MSCs, but we did not observe any adverse effect in histopathological examination.

The fact that NO levels are increased in the exhaled breath condensate of patients with asthma serves as a non-invasive means of

\section{B}

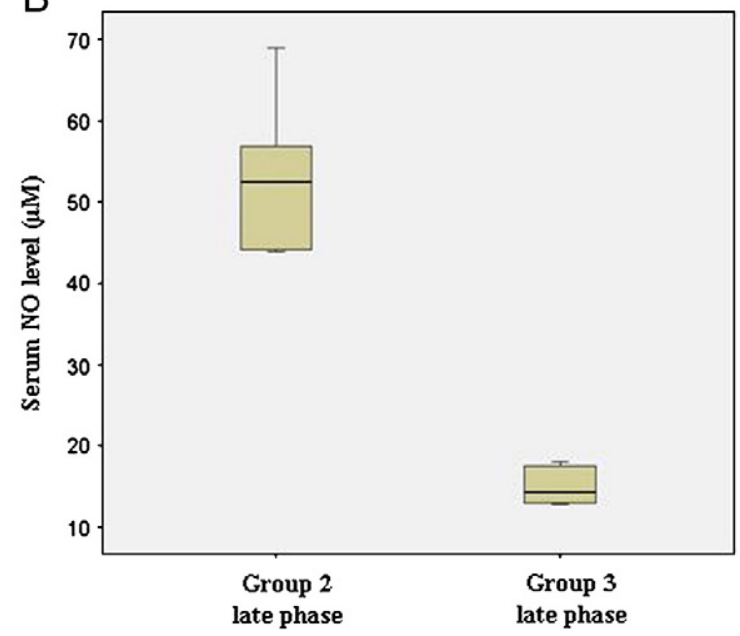

Fig. 5. A) The comparison of serum NO levels in the early phase between Groups 2 and 3. B) The comparison of serum NO levels in the late phase between Groups 2 and 3 . 
inflammation in asthmatic airways [37]. Increased exhaled NO levels in asthmatics were reported to be due to the release of NOS II enzyme in the airways and normalization of NO levels was demonstrated after steroid therapy [38]. Moon et al. demonstrated that production of inducible NO in lung tissue after OVA challenge of mice was inhibited by curcumin and they also demonstrated that supplementation with curcumin in human epithelial cells decreased iNOS and NO production induced by IFN- $\gamma$ [39]. In our study we could not study NO levels in exhaled breath because of the absence of condensator. However, we could study NO levels in serum with Griess method. The results of NO levels in serum indicated that MSCs were effective on decreasing NO levels. NO levels in serum can also be an indicator of inflammation in asthmatic airways. It could be hypothesized that the alterations of NO levels may lay behind the antiasthmatic effect of MSC as also shown in our study.

There were some limitations of our study such as cytokine levels could not be evaluated and the results found in our study may not be translated to positive findings in human clinical trials. In this study, in order to determine the effects of MSCs in the treatment of chronic asthma, we evaluated only histological changes and serum NO levels. Most of the asthma models are devoid of the chronic histopathologic changes seen in human asthma because of short-term exposure to inhaled antigen. Temelkovski et al. suggested that this experimental model replicated many features of human asthma [10]. Although we could only evaluate the histological changes of asthma, the validity of our method increases the value of our study.

Our results pointed to the ameliorating effects of MSCs on the chronic changes in the airways of asthmatic mice. Further studies with long-term treatments, which evaluate the effects of MSCs on lung inflammation and remodeling, are needed.

\section{References}

[1] Hansel TT, Barnes PJ. Novel drugs for treating asthma. Curr Allergy Asthma Rep 2001;1(2):164-73.

[2] Kumar RK. Understanding airway wall remodeling in asthma: a basis for improvements in therapy? Pharmacol Ther 2001;91(2):93-104

[3] Rizza MC, Sole D. Inhaled corticosteroids in the treatment of respiratory allergy: safety vs. efficacy. J Pediatr (Rio J) 2006;82(5 Suppl):S198-205.

[4] Sumi Y, Hamid Q. Airway remodeling in asthma. Allergol Int 2007:56(4):341-8.

[5] Payne DN, Rogers AV, Adelroth E, Bandi V, Guntupalli KK, Bush A, et al. Early thickening of the reticular basement membrane in children with difficult asthma. Am J Respir Crit Care Med 2003;167(1):78-82.

[6] Pittenger MF, Mackay AM, Beck SC, Jaiswal RK, Douglas R, Mosca JD, et al Multilineage potential of adult human mesenchymal stem cells. Science 1999;284 (5411):143-7.

[7] Loebinger MR, Janes SM. Stem cells for lung disease. Chest 2007:132(1):279-85.

[8] Iyer SS, Co C, Rojas M. Mesenchymal stem cells and inflammatory lung diseases. Panminerva Med 2009;51(1):5-16.

[9] Siniscalco D, Sullo N, Maione S, Rossi F, D'Agostino B. Stem cell therapy: the great promise in lung disease. Ther Adv Respir Dis 2008;2(3):173-7.

[10] Temelkovski J, Hogan SP, Shepherd DP, Foster PS, Kumar RK. An improved murine model of asthma: selective airway inflammation, epithelial lesions and increased methacholine responsiveness following chronic exposure to aerosolised allergen. Thorax 1998;53:849-56.

[11] Olmez D, Babayigit A, Uzuner N, Erbil G, Karaman O, Yilmaz O, et al. Efficacy of sulphasalazine on lung histopathology in a murine model of chronic asthma. Exp Lung Res 2008;34:501-11.

[12] Baran Y, Ural AU, Avcu F, Sarper M, Elçi P, Pekel A. Optimisation of transfection of green fluorescent protein in pursuing mesenchymal stem cells, in vivo. Turk J Hematol 2008;25:172-5.

[13] Kozanoglu I, Boga C, Ozdogu H, Sozer O, Maytalman E, et al. Human bone marrow mesenchymal cells express NG2: possible increase in discriminative ability of flow cytometry during mesenchymal stromal cell identification. Cytotherapy 2009;11: 527-33.

[14] Baskin H, Ellermann-Eriksen S, Lovmand J, Mogensen SC. Herpes simplex virus type 2 synergizes with interferon-gamma in the induction of nitric oxide production in mouse macrophages through autocrine secretion of tumour necrosis factor-alpha. J Gen Virol 1997;78:195-203.

[15] Tagaya E, Tamaoki J. Mechanisms of airway remodeling in asthma. Allergol Int 2007;56:331-40.

[16] Bergeron C, Boulet LP. Structural changes in airway diseases: characteristics, mechanisms, consequences, and pharmacologic modulation. Chest 2006;129: $1068-87$.

[17] Loebinger MR, Aguilar S, Janes SM. Therapeutic potential of stem cells in lung disease: progress and pitfalls. Clin Sci (Lond) 2008;114:99-108.

[18] Olsson F, Denham M, Cole TJ, Hooper SB, Mollard R. Deriving respiratory cell types from stem cells. Curr Stem Cell Res Ther 2007:2:197-208.

[19] Conese M, Rejman J. Stem cells and cystic fibrosis. J Cyst Fibros 2006;5:141-3.

[20] Wang G, Bunnell BA, Painter RG, Quiniones BC, Tom S, Lanson NA, et al. Adult stem cells from bone marrow stroma differentiate into airway epithelial cells: potential therapy for cystic fibrosis. Proc Natl Acad Sci 2005;102:186-91.

[21] Siniscalco D, Sullo N, Maione S, Rossi F, D'Agostino B. Stem cell therapy: the great promise in lung disease. Ther Adv Respir Dis 2008;2:173-7.

[22] Eastham AM, et al. Epithelial-mesenchymal transition events during human embryonic stem cell differentiation. Cancer Res 2007;67:11254-62.

[23] Spees JL, Whitney MJ, Sullivan DE, Lasky JA, Laboy M, Ylostalo J, et al. Bone marrow progenitor cells contribute to repair and remodeling of the lung and heart in a rat model of progressive pulmonary hypertension. FASEB J 2008;22(4):1226-36.

[24] Gazdhar A et al. Bone marrow derived mesenchymal stem cells accelerate alveolar epithelial repair in vitro. Stockholm, Sweden, European Respiratory Society Congress; 2007, pp. 718s-719s.

[25] Lane $S$ et al. Embryonic stem cell engraftment in healthy and injured mouse lung. Stockholm, Sweden, European Respiratory Society Congress; 2007, pp. 719s-720s.

[26] Gupta N, Su X, Serikov V, Matthay MA. Intrapulmonary administration of mesenchymal stem cells reduces LPS induced acute lung injury and mortality. Proc Am Thorac Soc 2006;3:A25.

[27] Ortiz LA, Gambelli F, McBride C, Gaupp D, Baddoo M, Kaminski N, et al. Mesenchymal stem cell engraftment in lung is enhanced in response to bleomycin exposure and ameliorates its fibrotic effects. Proc Natl Acad Sci 2003;100: 8407-11.

[28] Rojas M, Xu J, Woods CR, Mora AL, Spears W, Roman J, et al. Bone marrow-derived mesenchymal stem cells in repair of the injured lung. Am J Respir Cell Mol Biol 2005;33:145-52

[29] Hashimoto N, Jin H, Liu T, Chensue SW, Phan SH. Bone marrow-derived progenitor cells in pulmonary fibrosis. J Clin Invest 2004;113(2):243-52.

[30] Epperly MW, Guo H, Gretton JE, Greenberger JS. Bone marrow origin of myofibroblasts in irradiation pulmonary fibrosis. Am J Respir Cell Mol Biol 2003;29(2):213-24.

[31] Phillips RJ, Burdick MD, Hong K, Lutz MA, Murray LA, Xue YY, et al. Circulating fibrocytes traffic to the lungs in response to CXCL12 and mediate fibrosis. J Clin Invest 2004;114(3):438-46.

[32] Jordan CT, Guzman ML, Noble M. Cancer stem cells. N Engl J Med 2006;355(12): 1253-61 21.

[33] Rubio D, Garcia-Castro J, Martín MC, De la Fuente R, Cigudosa JC, Lloyd AC, et al. Spontaneous human adult stem cell transformation. Cancer Res 2005;65:3035-9 15.

[34] Aguilar S, Nye E, Chan J, Loebinger M, Spencer-Dene B, Fisk N, et al. Murine but not human mesenchymal stem cells generate osteosarcoma-like lesions in the lung. Stem Cells 2007;25(6):1586-94.

[35] Tolar J, Nauta AJ, Osborn MJ, Panoskaltsis Mortari A, McElmurry RT, Bell S, et al Sarcoma derived from cultured mesenchymal stem cells. Stem Cells 2007;25: 371-9.

[36] Karnoub AE, Dash AB, Vo AP, Sullivan A, Brooks MW, Bell GW, et al. Mesenchymal stem cells within tumour stroma promote breast cancer metastasis. Nature 2007;449:557-63.

[37] Hanazawa T, Kharitonov SA, Barnes PJ. Increased nitrotyrosine in exhaled breath condensate of patients with asthma. Am J Respir Crit Care Med 2000;162:1273-6.

[38] Carpagnano GE, Foschino Barbaro MP, Resta O, Gramiccioni E, Valerio NV, Bracciale P. Exhaled markers in the monitoring of airways inflammation and its response to steroid's treatment in mild persistent asthma. Eur J Pharmacol 2005;519(1-2):175-81.

[39] Moon DO, Kim MO, Lee HJ, Choi YH, Park YM, Heo MS, et al. Curcumin attenuates ovalbumin-induced airway inflammation by regulating nitric oxide. Biochem Biophys Res Commun 2008;375(2):275-9 17. 